\title{
Prophetic Visions in 1988: A Critical Reappraisal
}

\author{
Kenneth Ring, Ph.D. \\ University of Connecticut
}

ABSTRACT: This paper reviews the research into' a specific aspect of neardeath experiences (NDEs): the prophetic vision (PV). PVs are subjectively compelling flashforwards of planetary-wide cataclysms and eventual regeneration that sometimes occur during or in the immediate aftermath of an NDE. Previous research has shown that the most frequently mentioned year for the culmination of the geophysical calamities foreseen in PVs was 1988. I argue that PVs should be understood as manifestations of a collective prophetic impulse that historically tends to arise during periods of cultural crisis. PVs are thus expressions of the felt need for cultural renewal and therefore should not be taken literally as prognostic of drastic physical changes on Earth.

Ever since I first published my findings on prophetic visions (PVs) in the pages of this journal (Ring, 1982), I have repeatedly been asked whether I truly believed that their dark forecast for the planet would be our fate by the year 1988. Not surprisingly, the number of such inquiries increased after the release of my book Heading Toward Omega (Ring, 1984), in which I presented a more extended treatment of these disquieting phenomena.

As we entered 1988, the most frequently cited year for the culmination of the events in PVs, the issue of these PVs naturally reached another peak of salience for many persons who are familiar with the literature and lore of near-death experiences (NDEs). Accordingly, it now seems timely and appropriate for me to summarize the present state of our knowledge about PVs and to try to reassess their signifi-

Dr. Ring is Professor of Psychology at the University of Connecticut. Requests for reprints should be addressed to Dr. Ring at the Department of Psychology, University of Connecticut, Storrs, CT 06268. 
cance for our immediate future. This article, then, written in May 1988 , constitutes a lengthy reply of sorts to all those persons who have solicited from me my own private interpretation of this perplexing and troubling body of data.

Before exploring this matter in any depth, however, I must first review some of the basic features of PVs. To best appreciate the nature of PVs, it is useful to introduce them by making reference to an already well known aspect of NDEs to which PVs are clearly related, namely, the life review.

Everyone familiar with NDEs will recall that one of their common components is the panoramic life review in which, typically, the individual will report seeing in a series of extremely vivid and rapidly shifting images scenes depicting various events of his or her life extending back to very early childhood. Such impressions are extremely realistic, so much so that the individual may feel that he or she has in some very profound sense been enabled to "relive that life" so as to understand it from an entirely new perspective. All this is of course quite well known even to persons who have only a casual acquaintance with NDEs. What isn't nearly so widely understood, however, is the fact that sometimes persons experiencing a life review in connection with an NDE will also report having an apparent preview of their future. Appropriating a cinematic expression, I have labelled such apparent previews flashforwards. In such cases, it is as though the individual is lifted out of the on-going daily stream of mundane life and, for one moment outside of time, sees something like a life trajectory, extending in either direction from the present.

To illustrate these flashforwards here, I'll briefly recount the case of a woman who had a powerful NDE in 1972 while she was recovering from surgery. At one point during her NDE, she found herself facing what she described as an "enormous television screen." On the screen she was shown-in vivid color-various scenes from her life in a very rapid sequence of realistic images. Following that display, the screen disappeared but was followed by a second screen. That one, however, was dark and the images - in black and white this time-were much murkier and more difficult to discern. Nevertheless, she remembers being shown, among other events, the deaths of two members of her family (who were not ill at the time of this women's NDE) and told that she would play a special role in caring for these persons during their terminal illnesses. This NDEr has averred to me that these events, apparently disclosed during her flashforwards, did indeed come to pass. The same sincere avowals have been made by other NDErs I have interviewed who have also related their flashforwards to me (see Ring, 
1982,1984 ), and I have furthermore provided some evidence suggestive of independent corroboration for such claims. In any case, such flashforwards do seem to represent a genuine precognitive aspect of NDEs and merit further study.

Now as it happens not all of these NDE-related flashforwards pertain solely to the personal future of the individuals who experience them. Some of them instead have a planetary focus and seem to picture something of the earth's future. It is that type of flashforward I have called the prophetic vision, and it is that phenomenon to which this article is addressed.

What, then, do we now know about these PVs?

First, they are usually reported to occur during or in the immediate aftermath of an NDE and take the form of a distinct vision. That is, the events comprising a PV are typically beheld by the experiencer.

Second, PVs are apparently disclosed only in a relatively small proportion of cases involving NDEs, generally those that entail an unusually deep NDE as measured, say, by the Weighted Core Experience Index (Ring, 1980) or an extended period of clinical death. In my own investigations, for example, I have so far encountered only about two dozen persons who have described in some detail their PVs to me, either in personal interviews, lengthy letters or cassette tape recordings. That number of course represents only a tiny fraction-certainly less than 5 percent-of all the NDErs I have had contact with since I began my research in 1977.1

Third, PVs have been investigated and reported by a number of other researchers besides myself including Raymond Moody (personal communication, February, 1988), ${ }^{2}$ John Audette (1981), and Margot Grey (1985) whose work on this subject I will examine below.

Finally, and most important of all, PVs tend to follow a single, common scenario. That is, just as NDEs themselves seem to reflect a prototypic pattern, so also do PVs. Indeed, I personally have so far not found even a single obvious exception to the general pattern to be described next and, to the best of my knowledge, neither have other researchers.

What is the general scenario of these PVs? The summary I originally gave in my 1982 article still holds and is reproduced below:

There is, first of all, a sense of having total knowledge, but specifically one is aware of seeing the entirety of the earth's evolution and history, from the beginning to the end of time. The future scenario, however, is usually of short duration, seldom extending much beyond the beginning of the twenty-first century. The individual reports that in this decade there will be an increasing incidence of earthquakes, volcanic 
activity and generally massive geophysical changes. There will be resultant disturbances in weather patterns and food supplies. The world economic system will collapse, and the possibility of nuclear war or accident is very great (respondents are not agreed on whether a nuclear catastrophe will occur). All of these events are transitional rather than ultimate, however, and they will be followed by a new era in human history, marked by human brotherhood, universal love and world peace. Though many will die, the earth will live. While agreeing that the dates for these events are not fixed, most individuals feel that they are likely to take place during the 1980s. (Ring, 1982, pp. 55-56)

To exemplify this scenario in general terms, I'll cite a written account furnished to me by a woman I originally interviewed in California. Reinee Pasarow was seventeen when she had her NDE in 1967.

\begin{abstract}
The vision of the future I received during my near-death experience was one of tremendous upheaval in the world as a result of our general ignorance of "true" reality. I was informed that mankind was breaking the laws of the universe, and as a result of this would suffer. This suffering was not due to the vengeance of an indignant God, but rather like the pain one might suffer as a result of arrogantly defying the law of gravity. It was to be an inevitable educational cleansing of the earth that would creep up upon its inhabitants, who would try to hide blindly in the institutions of law, science, and religion. Mankind, I was told, was being consumed by the cancers of arrogance, materialism, racism, chauvinism, and separatist thinking. I saw sense turning to nonsense, and calamity, in the end, turning to providence. At the end of this general period of transition, mankind was to be "born anew," with a new sense of his place in the universe. The birth process, however, as in all the kingdoms, was exquisitely painful. Mankind would emerge humbled yet educated, peaceful, and, at last, unified. (Ring, 1982, p. 56)
\end{abstract}

As I have indicated, my own work on PVs was published between 1982 and 1984. During that period, an English psychologist, Margot Grey, was quietly collecting her own data on PVs, which she published in her book on NDEs, Return from Death, in 1985. Since her research is not well known in this country, but represents the most recent compilation of PV cases, it will be useful to summarize it here to round out the empirical portion of this paper.

Although Grey does not report the exact number of NDErs she interviewed who furnished accounts of PVs, her respondents' statements seemingly mirrored my own, even down to small specific points. This similarity can be appreciated if I simply pair one of Grey's representative quotations with one from my own respondents in order to 
illustrate some of the principal features that together comprise the typical prophetic vision.

\section{Earthquakes}

There are going to be a lot of upheavals such as earthquakes and volcanoes occurring in the next few years, which are going to get increasingly worse. I was given to understand that these activities are a reflection of all the social upheaval and violence that is going on all over the world at the moment. (Grey, 1985, p. 125)

The seismic activity is going to increase terribly and the United States is going to start suffering some great seismic problems. (Ring, 1984, p. 199)

\section{Volcanoes}

Among the many volcanic eruptions that are going to occur, I saw the one that just occurred in Hawaii. As I saw the pictures on the television, it was really quite uncanny, as I had already seen it taking place during the vision I had seen at the time of my near-death experience. (Grey, 1985, p. 125)

I was shown Mt. St. Helen's eruption. . . . I was also shown other volcanoes. . . . I was shown Mt. St. Helen's . . . and on May 18, Mt. St. Helen's really erupted its heaviest. I turned to my husband and said, "Mt. St. Helen's just blew its top," and the people there just laughed at me. Later that night we were watching TV and the very scenes that I had seen in my mind were shown on the TV and no one continued to laugh at me then. (Ring, 1984, p. 200)

\section{Geographical changes}

The poles are going to shift. I saw the earth stretching and groaning while giving birth to a new consciousness. I saw that every so often in the history of the world this happens and is inevitable in order for the earth to bring forth a new state of evolution. (Grey, 1985, p. 126)

There may be a pole shift ... there are going to be polar changes ... it's not going to kill all the races off, but we're going to have to start again from square one. ... There's going to be a larger land mass. (Ring, 1984, p. 200)

\section{Meteorological changes}

There are going to be very severe droughts in many countries. Others are going to suffer from freak storms that will cause tidal waves or 
flooding to happen as a result of unnaturally heavy rainfalls. . . All in all, the weather is going to be very unpredictable from now on, in fact these disturbances in the weather patterns have already started. (Grey, 1985, p. 127)

Oh, my God, that's going to be terrible. The weather is going to go crazy. We're just as likely to have snow in the middle of the summer nowadays as one hundred degree weather. . . I see droughts in other countries. (Ring, 1984, p. 201)

\title{
Food shortages
}

There are going to be serious food shortages around the world due to droughts in many places. This will push the price of food up so that many people will have to start going without things that they have always taken for granted. (Grey, 1985, p. 127)

We'll start getting more droughts, which will bring about shortages in crops and the shortage in crops will cause food prices to rise, which will cause a strain on the economic situation, which is already going downhill. Also at the same time . . because of the shortage of food and the failing economy, I see a strengthening of arms which causes tension.... These kinds of hostilities and (increasing) inflation start more hostilities. (Ring, 1984, p. 201)

This period of cataclysmic destruction will, according to the PV scenario, be followed by a new social order imbued with the ethos of a Golden Age. On this matter, too, Grey's respondents appear to agree with mine:

\begin{abstract}
After the darkest hour had passed away, during which time all the former things of this world had disintegrated and decayed, I saw a new consciousness emerging and mankind evolving in a new form. Thereafter I beheld a Golden Age in which people would live in love and harmony with each other and all of nature. (Grey, 1985, p. 133)

At the end of this general period of transition, mankind was to be "born anew," with a new sense of his place in the universe. The birth process, however, as in all the kingdoms, was exquisitely painful. Mankind would emerge humbled yet educated, peaceful, and, at last, unified. (Ring, 1984, p. 198)
\end{abstract}

As to when all of this is to take place, my earlier findings - when respondents were able to specify a particular year-tended to converge on a single date: 1988 . That is, this was the modal year mentioned as being the critical time.

What do Grey's respondents have to say on this point? In speaking 
specifically of some sort of nuclear disaster or new world war, we have these representative statements:

I think towards the end of this decade there is a very grave danger that we will become involved in a Third World War. I would say 1988 is the most likely year for it all to happen. (Grey, 1985, p. 130)

As time does not exist in the dimension where it is possible for this information to be given and received, it's very difficult to be accurate on this point. But the impression I gained was that the most difficult time was going to be around 1988. (Grey, 1985, p. 130)

I think the most likely year for the events I can see arising to take place will be in 1988. (Grey, 1985, p. 131)

Again, a most remarkable-if highly alarming-convergence of impressions. For whatever reason, 1988 was perceived by PVers on both sides of the Atlantic as being the year when the most catastrophic aspects of the vision were most likely to become evident.

That, then, summarizes the data we have on NDE-related PVs. Although the samples of PVers are to be sure very small, the degree of congruence among these independent respondents is impressive and, for that reason alone, deeply disturbing.

The crucial question, obviously, is just what are we to make of these data-in this possibly fateful if not fatal year of 1988 ?

Let's move directly then to the matter of possible interpretations of these findings.

Are these PVs indeed prognostic of our immediate planetary future, or do they signify something else? And, in any case, how can we know?

\section{Interpretations of PVs}

In Heading Toward Omega, I considered a set of six interpretative possibilities for PVs, ranging from the psychological to the literal. There is no need for me to repeat these here, but, again primarily for those who are not familiar with my previous work on PVs, perhaps it would be useful to outline just a few of these possibilities before probing this issue more deeply.

One explanation would have it that because the NDE itself involves an obvious death-and-rebirth motif, PVers might psychologically inflate their experience and project it onto the world stage, as it were. That is, the imagery associated with their PVs should really be construed as representing the symbolic accompaniment to their own neardeath dramas, extended to global dimensions. Stanislav Grof (1975, 
1988), for example, has shown that the imagery of world cataclysm often occurs in conjunction with ego-death processes in psychedelic visions; perhaps something analogous takes place in NDEs but in that context tends to be interpreted literally because of the crisis of possible imminent physical demise.

Another interpretative alternative would point to the role of contemporary cultural factors, namely, the Zeitgeist of apocalyptic expectation. After all, we are within a dozen years of the end of our millennium and images of planetary death-throes are plentiful. We have only to think of Christian eschatology, the Hopi prophecies or the dark utterances of famous psychics of past and present, such as Nostradamus, Edgar Cayce, or Ruth Montgomery, in order to realize how abundant these notions are in our popular culture these days. Perhaps, then, some NDErs, being in an altered state of consciousness, are especially likely to tap into these apocalyptic visions that abound in our collective psychic field but misinterpret them as their personal visions.

Still another explanatory candidate is that there may be various alternative futures for our planet's destiny, and PVers have happened to zero in on one single track of possible but not inevitable futures. In this case, they have superimposed onto their glimpse of a possible future an interpretation of its certainty.

And lastly-the most dreaded option of all-perhaps these PVers have really been vouchsafed a vision of what is literally going to happen soon. In this case, their sightings would have predictive significance for what is actually in store for us before the end of this decade.

These are some of the interpretative possibilities that have occurred to me; doubtless you could generate further explanatory notions of your own. The urgent question, however, is how can we decide among such alternatives? Clearly, if we take these data seriously-and I, for one, do-it is of the utmost importance for our sanity to determine how we should relate to these visions.

Needless to say, I am not going to pretend that the answer can be known with absolute certainty-much less that $I$ happen to be in possession of it-but I believe I can offer a few helpful considerations here that will at least bring a measure of clarity to the interpretation of these images of planetary devastation and rebirth.

The first helpful hint was actually provided to me several years ago by a correspondent who had read my first article on PVs. She sent me some information on an NDE-induced PV she had learned about. And, sure enough, it did indeed conform to the familiar scenario that I have already outlined here. The gentleman who experienced this PV also 
felt that the transitional period of the earth's upheaval was imminent. In fact, there was only one feature of this PV that was in any way atypical, and that was when it had occurred. In this case, it had taken place nearly a century ago: 1892 !

Now, clearly, either this individual was considerably ahead of his time or there is a much greater historical relativity to these PVs than we might at first have supposed.

And, indeed, if one begins to look into the historical aspect just a little, one can find ample evidence that PVs are by no means restricted to modern times at all. Instead, as John Perry, among others, has recently shown in his cogently argued book, The Heart of History (Perry, 1987), many such PVs can be found throughout history, particularly in sensitive individuals whose cultures were undergoing a period of deep crisis.

Just to take one illustrative case to show the typical features of many of these historical PVs, consider that of Handsome Lake, a member of the Seneca-an Iroquois tribe-who lived in the early nineteenth century. During that period, the Seneca were already a people whose cultural integrity was nearly destroyed and Handsome Lake himself was deeply demoralized and despairing. According to Perry, he appears eventually to have sunk into a death-like coma and began to experience visions in which angels told him how his people could be saved. At one point, he found himself travelling along a bright road, sensed that he was following in the tracks of dead souls and ultimately encountered a brilliant light of the kind by now so familiar to students of the NDE. Following that, he had a vision of world destruction and great widespread sickness, but was given to understand that his mission was to prevent the catastrophe with the help of his angels and the Great Spirit.

Following his visionary revelation, Handsome Lake was charged with a tremendous zeal for reform and did in fact play an instrumental role in the regeneration of the Seneca nation, as history shows.

Now, of course, not all recipients of PVs have been as effective as Handsome Lake in following such social imperatives, but that is hardly the point. The central lesson for us instead is that history establishes the proposition that such prophets arise during times of cultural crisis and that they bring a messianic message of the need for cultural renewal. Again, to draw on Perry's insightful comments here:

The horrific vision of world destruction is part and parcel of the mythic imagery of rapid culture change and world views in transition.

... Beholding the world coming to its end amid storm, earthquake, 
flood and fire we have found to be a typical [italics added] experience of a prophet whose psyche is registering the emotional impact of the end of an era. The ensuing world regeneration is then the picture of the ushering in of a new age, meaning by this an innovative cultural effort whose configuration is outlined in a fresh myth. ... This pattern of transformation is basic to ... revitalization movements throughout history. (Perry, 1987, p. 192)

In other words, what we appear to have in modern NDE-inspired PVs is not the literal forecast of planetary doom, but rather the foreshadowing of the need for a new myth of cultural regeneration.

What I am asserting is that whereas PVs are indeed prophetic utterances, they should not, in my opinion, be regarded as truly precognitive or taken literally. Rather they seem to be reflections of the collective psyche of our time, which is generating its own images of planetary death and regeneration for which the sensitive souls of our era serve as carriers. Therefore, in my view it is important to avoid making what, to paraphrase Carl Jung, we could call the concretistic fallacy: taking an image of the psyche as representing literal fact rather than meaningful symbol. NDE-related PVs, then, tell us more about our collective psyche now than the probable state of our material world tomorrow, but they also contain the elements that point to the emergence of a new messianic movement in our time, one that is planetary in scope and for which the NDE phenomenon itself is pivotal.

But just here, having claimed for the NDE a special cultural role, we need once again to enlarge our angle of vision in order to encompass a wider view of the PV horizon. Just as these experiences are hardly limited to the modern era, so they obviously do not only occur with the onset of a deep NDE. Other persons who, like the NDEr, have had unusual psychospiritual experiences that transcend the boundaries of time and space likewise sometimes share the same prophetic revelations reported by NDErs.

Perhaps the most salient exemplar of such insights, besides the NDEr, in the waning years of the 1980 s, is the individual who has had some kind of profoundly life-altering "UFO encounter." 3

That is, I believe, quite evident in both the recent spate of UFOrelated literature as well as that which goes back to the heyday of the so-called "contactees" of the 1950 s. For instance, no one who reads Communion (Strieber, 1987), the best-selling recent book detailing one man's extraordinary experiences with otherworldly visitors, can fail to note its tone of urgency and prophetic significance. And what the 
author-who has since become the most celebrated, if controversial, figure in the UFO movement of the past decade-found latent in his own private experiences can be discovered at large in the UFO encounter reports of the past. As Strieber himself commented:

Throughout the literature of [UFO] abduction, there is a frequent message of apocalypse ... a general expectation of catastrophe. (p. 288)

My own reading of some of the professional literature in the field (e.g., Jacobs, 1975; Andrews, 1986; Davis, 1988; Sprinkle, 1982) and informal conversations with many of those-investigators and experiencers alike-active in UFO studies today have convinced me that Strieber is correct in his assessment. There is little doubt in my mind that one finds among many UFOers-if I may adopt the term-a heightened concern with the prospect of global catastrophe and the need for planetary transformation. In that respect, the views of such persons and NDErs appear to represent an intriguing pattern of similarity whose significance will not be lost on present-day cultural historians.

At this level, obviously, we are no longer dealing with NDErs and UFO encounters merely as fascinating psychospiritual experiences possibly pointing to a transcendental dimension of life. Instead, we are beginning to see them-with their prophetic implications-in their collective and mythic aspect and to discern in them the power to function as social forces in the service of planetary transformation.

\section{PVs and the Voices of Prophecy}

In discussing NDEs and UFO encounters in light of their collective, sociological meaning and in the context of their prophetic import, I mean to suggest something new and specific about the prophetic impulse in our own time. Historically - and biblically for that matter-we are accustomed to the notion of the individual prophet and his or her message of the need for regenerative transformation. The instance of Handsome Lake, for example, can stand for the special role of the lone prophet as the agent of the forces of renewal in the prophet's own culture.

Similarly, we are all familiar with the idea that certain gifted individuals - the artist or poet-can also serve a prophetic function for their 
contemporaries. Here, for example, we may profitably recall Shelley's words:

Poets are the hierophants of an unappreciated inspiration; the mirrors of the gigantic shadows which futurity casts upon the present. (Woodman, 1964, p. 71, citing Shelley's "Defense of Poetry" [cited in Perry, 1987])

What is true in our own time, I submit, is that this prophetic function is becoming democratized: ordinary men and women in increasingly great numbers are being gifted with profound soul-opening experiences that carry the charge of prophetic revelation. I am speaking of course of NDErs and UFOers, among others, those millions of persons who have been "tapped" by higher energies to be the carriers of this message of renewal to the planet as a whole.

These persons, I believe, are the true visionaries of our time, the bearers of the emerging myth of the twenty-first century calling us to a cosmic-centered view of our place in creation, a myth that has the power to ignite the fires of worldwide planetary regeneration and thus to save us from the icy blasts of Thanatos's nuclear winter.

The question naturally arises: How and why is this happening?

Any answer with pretensions to definitiveness would of course be the height of presumption, but many before me have suggested that it has something to do with the unprecedented peril that the earth has faced for the last 40 years, ever since the dawning of the Nuclear Age and the simultaneous emergence of UFOs as a planetary phenomenon. And a number of thinkers have in this connection invoked the concept of something like a planetary mind that is not separate from yet is more than the sum of our individual minds and that seems to serve as the controlling agency mediating all this. Jung, of course, would call that "the collective unconscious"; Terence McKenna, one of the most original visionary thinkers of our own day, speaks of "The Overmind" (McKenna, 1983); ufologist Jenny Randles prefers "The Species Mind" (Randles, 1987); but the formulation I like best is that of Michael Grosso, who has proposed we revive Aldous Huxley's serviceable phrase "Mind at Large" (Grosso, 1985).

Rather than try to describe Grosso's ideas at this point, let me simply refer you to his brilliant and compelling book, The Final Choice (Grosso, 1985), or, failing that, to my extensive review of it (Ring, 1988). Suffice it to say that I endorse his formulation especially because he is one of the few who has so far made the explicit connection, 
as I have tried to do here, between NDEs and UFO encounters in terms of their collective prophetic function-all orchestrated by Mind at Large. Instead of trying to summarize his argument here, I'd like just to quote a few passages from the concluding portion of his book. These will be sufficient to help draw together into one tight knot the few remaining loose threads of the thesis I've been fashioning in this essay.

The collective unconscious of humankind is in a state of unrest. The Bomb is causing Mind at Large to reverberate with monitions of disaster and visions of a new earth.

Let us then examine three types of prophetic visionary experience: near-death visions-especially the "prophetic" subset; UFO "contactee" cults; and visions of the Blessed Virgin Mary. All follow a common pattern and stem, I conjecture, from the same adaptive mechanism of the collective unconscious: they are part of the configuration called the archetype of death and enlightenment. What might this mean for the evolution of human consciousness? Are there indeed evolutionary stirrings in the collective psyche at the present time? Comparing these visionary experiences, perhaps the reader will be persuaded that there are. (Grosso, 1985, p. 303)

After reviewing these three types of prophetic experiences, Grosso goes on to ask:

What is the function of these extraordinary experiences? The answer is clear. In all, it is to warn and to transform. Apocalyptic visions deal in futures. Eschatology is probabilistic, catastrophe is conditional. The ultimate message: it's up to us; a bright and multi-colored flag, against a dark horizon, waves us on to action.

Images of ruin rise up from the misty deeps of the world soul; the rough beast slouches toward Bethlehem to be born. In an age foreshadowing nuclear winter, we are all summoned to be magi, to form a network of magi, to hazard the desert and follow where strange stars lead. These lights that flash from the heaven of Mind at Large inspire us to say farewell to the old, the life-denying self. They give us glimpses of where we could go and charge us with the energy to go there. The function of the visions is pretty much the same: to grant courage to change in heart and soul, to sacrifice the gift of ourselves to the infant god of our own higher future. They help us to make the final choice, to take the leap beyond death to new life. (Grosso, 1985, pp. 313-314)

In the last heartbeat before eternity, the soul sends up its messages of guidance and consolation. The universal adaptive mechanism of the archetype of death and enlightenment is awakened in life-threatening situations. This is clear in near-death visions. In very deep near-death visions, the adaptive information goes beyond the personal; it addresses the transpersonal and takes the form a general apocalypse. 
UFO revelations entered a new phase in 1947 in the wake of the first atomic bombings, events bound to cause a stir in the collective consciousness. UFO revelations, in my view, are part of the response to the increasing risk of nuclear war. They register perturbations in the collective psyche.

UFO and near-death visionaries are clear on this: their visions are given to assist humanity at large in the transition to new forms of life. The earth itself is in need of transformation; we need to learn to adapt to a new earth because the old earth is passing away. Churned out by the collective unconscious, the vision is a map of global near-death and inner transformation. It is also a response to a life-threatening situation. The species, not just the individual, is on the threshold of near-death. Indeed, all species of life are threatened; hence, catastrophe is pictured in geologic imagery. Person and planet are at risk; this type of prophetic imagery is "designed," it would appear, to provide a perspective with survival value. (Grosso, 1985, pp. 314-315)

Clearly this reading of the significance of PVs does not lead to fatalism but to action. Rather than taking these images literally, we must see them as harbingers of hope that point to the possibilities of human regeneration and planetary transformation. Despite our difficulties, we can take heart that millions of people have apparently been recruited by Mind at Large to help actualize through their own being and behavior this emerging myth; they are today's messengers of hope (Parrish-Harra, 1983), the voices of prophecy.

It seems appropriate to conclude this article with one final quote from a PVer whose reflections on her experience match exactly my own convictions concerning the hortatory significance of the PVs we've considered here:

During my experience ... I was also shown events that are likely to happen in the near future, but was made to understand that nothing is absolutely fixed and that everything depends on how we choose to use our own free will, that even those events that are already predestined can be changed or modified by a change in our own way of relating to them. (Grey, 1985, p. 123)

Our task, then, is to defuse these images by de-literalizing them. By thus robbing them of their power to freeze us into postures of passive fear, we may reap their mythic potential for planetary transformation as we head into the new millenium that awaits us.

\section{Reference Notes}

1. There are two factors, however, that need to be noted here that might have led me (and others) to underestimate the proportion of such cases in the population of 
NDErs. The first is that I personally have not made any special search for PVers since March, 1981; had I been diligently seeking such individuals I suspect I could have found quite a few more. Second, since most researchers who have interviewed NDErs did not interrogate their respondents about this type of experience, it may in fact be more common that we suppose. Moreover, because of the content of the prototypic PV, it would be understandable that some if not most NDErs would be reluctant to mention it, even to a sympathetic interviewer.

2. Moody has never chosen to publish the material he has collected on the subject of PVs, but he has generously shared his findings privately with me and other re searchers many times over the years, the most recent occasion being in New York in February, 1988.

3. I don't want to take the time to discuss the nature of these encounters, which is a subject of high controversy both within and outside of UFO circles. I do want to state, however, that I think the term "UFO encounter" is quite unfortunate since there is in my opinion no persuasive evidence that, despite the subjective reality of these experiences, they have anything to do with "flying objects," much less "extra-terrestrials," as such. Nevertheless, I will bow to the widespread currency of the phrase and use it, although reluctantly, in this context.

\section{References}

Andrews, G. (1986). Extraterrestrials among us. St. Paul, MN: Llewellyn.

Audette, J. (1981). Visions of knowledge in NDEs. Vital Signs, 1 (4), 5-6.

Davis, L. (1988). A comparison of UFO and near-death experiences as vehicles for the evolution of consciousness. Journal of Near-Death Studies, 6, 240-257.

Grey, M. (1985). Return from death. London, England: Arkana.

Grof, S. (1975). Realms of the human unconscious. New York, NY: Viking.

Grof, S. (1988). The adventure of self-discovery. Albany, NY: State University of New York Press.

Grosso, M. (1985). The final choice. Walpole, NH: Stillpoint.

Jacobs, D. (1975). The UFO-controversy in America. Bloomington, IN: Indiana University Press.

McKenna, T. (1983). The definitive UFO tape [cassette recording]. Big Sur, CA: Dolphin Tapes.

Parrish-Harra, C. (1983). Messengers of hope. Black Mountain, NC: New Age Press.

Perry, J. W. (1987). The heart of history. Albany, NY: State University of New York Press.

Randles, J. (1987). Beyond explanation? New York, NY: Bantam.

Ring, K. (1980). Life at death. New York, NY: Coward, McCann and Geoghegan.

Ring, K. (1982). Precognitive and prophetic visions in near-death experiences. Anabiosis. The Journal of Near-Death Studies, 2, 47-74.

Ring, K. (1984). Heading toward omega. New York, NY: William Morrow.

Ring, K. (1988). Review of The final choice. ReVision, 10 (3), 39-44.

Sprinkle, R. L. (Ed.). (1982). Proceedings, Rocky Mountain conference on UFO investigation. Laramie, WY.

Strieber, W. (1987). Communion. New York, NY: Beech Tree Books.

Woodman, R. C. (1964). The apocalyptic vision in the poetry of Shelley. Toronto, Ontario: Toronto University Press. (Cited in Perry, J. W. (1987). The heart of history. Albany, NY: State University of New York Press.) 